\title{
The Respiration of Plants under Various Electrical Conditions.
}

BY

\author{
R. C. KNIGHT
}

AND

\author{
J. H. PRIESTLEY, \\ Botanical Department, University of Leeds. \\ With six Figures in the Text.
}

INTRODUCTION.

$\mathrm{T} \mathrm{N}$ a large number of field experiments carried out during recent years, 1 plants, otherwise under normal conditions, have been subjected to an electric discharge from an overhead system of wires during a considerable portion of their growing period, and, as a result, acceleration of growth and increase in yield have been constantly reported.

It has been pointed out in a résumé of these experiments, published by one of us, ${ }^{1}$ that this treatment must considerably alter many factors in the plant habitat and in the plant's reaction to this habitat, and consequently it is difficult to ascribe the effect, apparently due to the electric discharge, to any particular physiological cause.

This paper records some of the first results of an attempt to analyse the effect of the discharge upon the plant by an investigation, under laboratory conditions, of the effect produced by such discharge upon one physiological function of the plant.

The particular function first selected for investigation was respiration in so far as this is measured by the output of carbon dioxide, in part because this can be estimated fairly accurately, but more especially because it was considered that the amount of carbon dioxide evolved by the plant would give a good indication of the progress of katabolic processes within the plant. Attention was directed to these katabolic processes because it was thought that an increase of available energy within the plant might explain the general acceleration of growth upon electrification, which has been so characteristic a feature of the reports of the field trials.

1 Journal of the Board of Agriculture, vol. xvii, p. 14.

[Annals of Botany, Vol. XXVIII. No. CIX. January, 1914.] 
Attention has been for some time directed to the apparent acceleration of growth and maturation reported in field trials, because this phenomenon rendered it impossible to gauge the extent to which increased yield was a direct result of electrification. If a crop matures earlier, and particularly if it is therefore harvested earlier, it may mean that the plants are not exposed to a period of bad weather during which the yield, instead of improving, may actually decrease in amount. If acceleration is a result of treatment, it needs to be considered in all cases where the causes of an increased yield have to be analysed. It therefore seemed desirable to arrive as soon as possible at a decision as to the possible cause of such an acceleration as has been reported in many field trials. The results obtained in these trials have been given at length elsewhere, ${ }^{1}$ but in view of the importance of the question of acceleration in relation to the subject-matter of the present paper, it will perhaps be advisable to extract from the previous reports the data which formed the foundation for this research, and to subject them to further criticism in the light of later work.

\section{ANalysis of Results of Field TRials.}

In the earliest experiments at Bitton, with an inefficient influence machine driven by an oil engine as the source of electrical power, and with the overhead wires close to the plants to be treated, the following results, amongst others, were obtained :

Broad beans. Decrease in yield of I 5 per cent., but ready for picking five days earlier than the control.

Spring cabbages. Ready for cutting ten days earlier.

In all the other experiments from which data have been taken, the Lodge-Newman system of electrification, described in previous papers, ${ }^{2}$ has been used.

At Evesham in 1906 the Canadian wheat under electrical treatment was ready for cutting some three or four days before that of the control area. In the case of the English wheat, the time of ripening was unchanged by electrification, and it is perhaps significant that the yields in the two cases were as follows:

$\begin{array}{lccc} & \text { Bushels per acre: } & \\ & \text { Electrified. } & \text { Non-electrified. } & \text { Increase. } \\ \text { Canadian (Red Fife) } & 35^{\frac{1}{2}} & 2^{\frac{1}{2}} & 39 \% \\ \text { English (White Queen) } & 4^{\circ} & 3^{\mathrm{I}} & 29 \%\end{array}$

Results which indicate a greater increase in yield in the crop showing acceleration in rate of growth.

1 Journal of the Board of Agriculture, loc. cit, and also vol. xx, p. $5^{82}$.

2 Journal of the Board of Agriculture, loc. cit., also Journal of the Royal Horticultural Society, vol, xxxvii, p. I5. 
Strawberries at Evesham have on several occasions shown marked acceleration. Thus in 1907 :

First complete picking, June 28 th, Electrified $5^{6} \mathrm{lb}$.

", " Control $33 \mathrm{lb}$.

The size of the area electrified was only $5^{6}$ per cent. of the size of the control area, so that this relative yield, if maintained, would mean an increase of about 200 per cent. as the result of electrification; but the effect was mainly acceleration, and the final difference in yield between the two plots represented an increase of only 25 per cent.

In 1908 the results with strawberries were as follows:

Pickings, June 20 th and 22nd. (Areas as in 1907.) Electrified $\mathrm{I}, 3 \mathrm{I} 8 \mathrm{lb}$.

Control I, $876 \mathrm{lb}$.

This yield maintained would represent an increase of about 25 per cent., but the total pickings actually showed 9 per cent. less strawberries from the electrified area.

Similarly with tomatoes at Evesham in 1908 ; the early pickings up till September 24, when compared with the total yield, show marked acceleration in ripening under electrification.

1b. per plant till Sept. 24th

lb. per plant total yield

\begin{tabular}{cc}
\multicolumn{2}{c}{ Electrified. } \\
$A$ & $B$ \\
$\mathrm{I} \cdot 36$ & $0.3^{6}$ \\
4.29 & 3.5
\end{tabular}

Control.

0.10

$2 \cdot 4$

From these figures it is evident that the yield from the control plants in time approaches that from the electrified. The reasons for expressing the yields from the electrified area in two sections, $A$ and $B$, is that whilst plot $A$ was, as far as could be ascertained, exactly comparable with the control, the plot $B$ was slightly favoured as regards aspect and also irrigation.

In the Bitton experiments in 1908 , where cucumbers under glass were grown under electrification, the yields in the first month seemed to indicate distinct acceleration, and are therefore given in full. They correspond to the time before the plants had grown up behind the supporting wires, which later effectually screened them from the discharge. The pickings were usually made three times a week; the dates are given in the top line of the following table :

\begin{tabular}{|c|c|c|c|c|c|c|c|c|c|c|c|c|}
\hline & No. & of $\mathrm{Cl}$ & umber & gathe & red on & April: & & & & & & Total \\
\hline $\begin{array}{l}\text { House } \\
\text { No. }\end{array}$ & & loth & I 3 th & I5th & $\mathrm{I}$ th & $20 t h$ & $22 n d$ & $24^{t h}$ & $27 t h$ & $29^{t h}$ & Total. & $\begin{array}{c}\text { for } \\
\text { Season. }\end{array}$ \\
\hline I & Control & - & - & 8 & 12 & I 7 & 14 & 27 & 69 & 67 & $2 I_{4}$ & 2,410 \\
\hline 2 & & - & I4 & 34 & 86 & 108 & 82 & 23 & 22 & 24 & 393 & 2,477 \\
\hline 3 & Electrified & 8 & $5 \mathrm{I}$ & 63 & I 24 & 93 & 5 & 10 & 3 & 48 & 485 & 2,753 \\
\hline 4 & " & I5 & 67 & 64 & IIO & $9^{8}$ & $5:$ & I I & 26 & $4^{\mathrm{I}}$ & 487 & 2,710 \\
\hline 5 & ", & 12 & 55 & 53 & 87 & 95 & $3^{8}$ & 14 & 33 & 37 & 424 & 2,729 \\
\hline
\end{tabular}


The foregoing data indicate that the acceleration effect occurs sufficiently frequently to be worth analysis, but a further study of the method of carrying out a field experiment has thrown a considerable amount of doubt upon the conclusions they have so far suggested.

When the distribution of the electric discharge from an overhead system of wires is studied by electrical methods, it soon becomes clear that any electrical effect produced will not be restricted to an area of ground just beneath the wires. On the contrary, when the slope of electric potential is mapped over the field, the effect of the discharge is seen to spread a number of yards on all sides of the outer wires, and when a wind is blowing the current is carried a very long distance down the wind. ${ }^{1}$ Thus, when the matter is investigated, it may happen that a point on the control, as far removed as possible from the overhead wires, may be receiving about one-tenth the current per unit area that the ground directly. beneath the overhead wires is receiving, while a proper control, obtaining only the normal atmospheric discharge, would receive at most a current that was ten thousand times less than that under the wires. Under such conditions it is clear that the control plot fails in its object. An attempt is now being made in the field (at Lincluden Mains, Dumfries) to determine the question as to whether acceleration really takes place under more rigorous experimental conditions, i. e. with a control as carefully screened from additional electric discharge as is practically possible.

It is perhaps worth pointing out that the most consistent reports as to acceleration have come from the Evesham experiments, where the areas have been large and where it is at any rate probable that the control area has to some extent been under normal conditions. ${ }^{2}$

Until some physiological analysis of the effect of electrification upon the katabolic and anabolic processes of the plant has been carried out, it is not possible definitely to attribute the increased yield to direct effect upon any single process in the plant.

The result of an investigation of the effect of electrical stimulation upon carbon dioxide output is given in the following pages, and although, under the conditions obtaining in our experiments, we have been able to record a distinct increase in carbon dioxide output during electrification, we have found that this increase can be wholly attributed to a rise of temperature, which takes place owing to the production of heat during the discharge. Thus we are led to conclude that the explanation of the acceleration phenomena recorded above is not to be found in the response of the respiratory function of the plant to electrification.

1 This is especially marked in recent experiments where the overhead wires are from 10 to 15 feet above the ground.

${ }^{2}$ For a fuller discussion of this question see paper in the Journal of the Board of Agriculture, vol, $\mathrm{xx}, \mathrm{p} .582$. 
This does not mean that an acceleration process, if present, is inexplicable. It may well be that one result of electrification may be increased transpiration; this alone would account for a more rapid attainment of maturity by the plant. The effect of such electrical conditions upon transpiration is now being investigated by the biophysicists of the Department of Agriculture in Washington.

The effect of electrical discharge upon the important anabolic processes of the plant is at present being further investigated, but it may be pointed out that an increased activity of constructive metabolism has been previously reported by Pollacci, Koltonski, Berthelot, and others.

This work, which has been in progress for several years, has been made possible only through various research grants that have been made from time to time. The work was started at Bristol as the result of a grant from the Colston Research Fund of the University of Bristol, and it has been possible to continue the investigation in the Botanical Department of the University of Leeds, owing to grants received from the special Research Fund placed at the disposal of the Board of Agriculture by the Development Commissioners.

During the progress of the work we have been led into fields very remote from the ordinary path of the botanist, and we have to acknowledge with gratitude the great help received from colleagues in other scientific departments ; especially have we to thank Dr. A. M. Tyndall, of the Physics Department, University of Bristol, and the staff of the Physics Department of the University of Leeds for continuous kindness and advice.

\section{EXPERIMENTAL.}

In the experimental investigation of the influence of electricity upon the carbon dioxide output, it was considered advisable to employ germinating seeds and young seedlings kept in the dark, so that the reverse process of photosynthesis was eliminated.

The methods of electrification were similar to those which have been tried in the field experiments, and they may be conveniently discussed under two heads, viz.:

I. Experiments with small direct currents at a relatively low voltage.

2. Experiments with electric discharge at high tensions.

Before giving an account of the methods of applying these electrical conditions, it will be advisable to describe the apparatus used in the determination of the carbon dioxide output, after which the alterations necessitated by different methods of electrification can be easily indicated.

The respiration was quantitatively determined by a volumetric method, the amount of carbon dioxide being calculated in grammes. The method was the same in all experiments, and was essentially that advocated by Detmer. ${ }^{1}$

1 Practical Plant Physiology, Eng. ed., I898, p. 264. 
A stream of air, free from carbon dioxide, was passed over the seeds or seedlings and afterwards passed through baryta solution to absorb the carbon dioxide which the living material had evolved. Before entering the respiration vessel, the air was passed through a series of wash-bottles containing a concentrated solution of potash, or, as in the later experiments, a long tube packed with soda-lime, in order to free it from carbon dioxide. To test the purity of the air-stream another wash-bottle containing clear baryta solution was inserted before the respiration chamber. After leaving the vessel containing the living material, the air-stream entered one of a series of Pettenkofer's tubes, containing a known volume of a standard solution of barium hydrate, which absorbed the carbon dioxide, precipitating barium carbonate, and finally the air-current passed through a second wash-

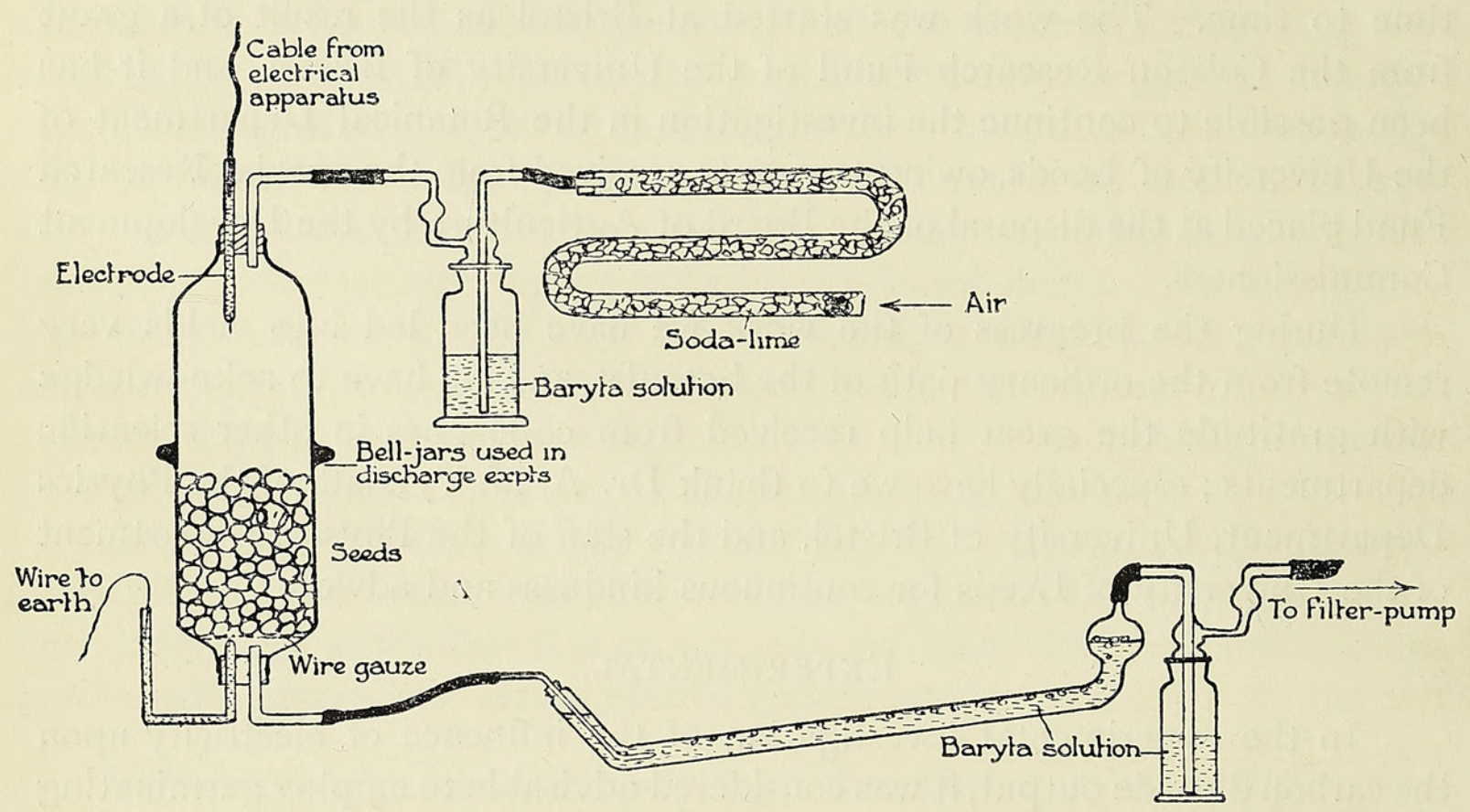

FIG. I.

bottle of clear baryta to ascertain whether or not all the carbon dioxide had been removed (Fig. I). Various methods of keeping the air-stream in motion were resorted to, including aspirators, filter-pump, and a gas-holder, but the most satisfactory was a water-pressure filter-pump, the water-supply for which was maintained at constant pressure by means of an overflow device. The rate of the air-stream was thus rendered independent of slight variations of the water pressure from the main, which were found very troublesome at first.

When seeds were employed, they were soaked in water for at least twenty-four hours before being experimented upon, and immediately before being introduced into the respiration chamber, the water was drained off and the seeds dried somewhat in a cloth. This removed the excess water from the outside, thus preventing the accumulation of water in the tubes of the apparatus. 
The living material having been enclosed in the chamber, the airstream was drawn through the apparatus for a definite period-half an hour, an hour, or two hours,-depending upon the time required for the evolution of a measurable quantity of carbon dioxide.

The stream was then diverted through a second Pettenkofer tube for a similar period, and so on until the required number of determinations had been made. By means of two seven-way pieces of glass tubing and six Pettenkofer tubes, each capable of being closed separately by pinchcocks and rubber connexions, this transference of the air-stream from one tube to another was rendered rapid and easy.

The titration was carried out with standard oxalic acid solution. The baryta solution in the Pettenkofer was quickly transferred to a flask of about 125 c.c. capacity, so as to introduce as little atmospheric carbon dioxide as possible, corked and shaken.

After a few minutes the precipitate had settled and Io c.c. of the clear supernatant liquid were pipetted off into another flask and titrated from the acid burette, using phenolphthalein as indicator.

The standard solutions were kept in large bottles provided with siphoning tubes, which were attached to side tubes in the respective burettes. Air was admitted, both to stock bottles and burettes, only after passage through tubes containing sticks of potash, so as to prevent access of atmospheric carbon dioxide. The baryta solution contained approximately 9 grm. per litre, and was standardized by the oxalic acid solution, which was made up to $\mathrm{I} .432 \mathrm{grm}$. of the crystallized acid per litre, I c.c. of this solution being equivalent to $0.0005 \mathrm{grm}$. carbon dioxide. This, coupled with the fact that the volume of baryta in each Pettenkofer tube was exactly Ioo c.c., simplified the calculation of results.

Before entering upon the experiments under various electrical conditions, extensive control trials were carried out, in order to ascertain to what extent variations of carbon dioxide output might occur under the conditions of the experiment, apart from the influence of the electric current.

Determinations of the carbon dioxide evolved were made every halfhour from the moment the living material was introduced into the chamber, and continued without intermission for as many as six hours, the material being unelectrified the whole time. The figures obtained were then plotted against time, and a curve was thus obtained which gave an indication of the process of the respiratory function. During the investigation, as will be seen, it was found necessary to employ various types of respirationchambers, and with each type a series of these control experiments was carried out. 
i. Experiments with Small Direct Currents at Low Voltages.

In these experiments the respiration chamber was a glass tube about $30 \mathrm{~cm}$. long and $3.5 \mathrm{~cm}$. in diameter, with rubber stoppers at both ends fitted with two delivery-tubes. The current was applied at first through unpolarizable electrodes (Detmer, loc. cit., p. I57), but these were later replaced by simple mercury-platinum contact electrodes, as with these it was found that very little progressive reduction in current strength took place. Contact was ensured by shaking the seeds well together before inserting the rubber stoppers. Current strength was measured by a calibrated Paul millivoltmeter, shunted when necessary. In the later experiments a thermometer bulb was introduced through a side tube into the respiration chamber (see Fig. 2).

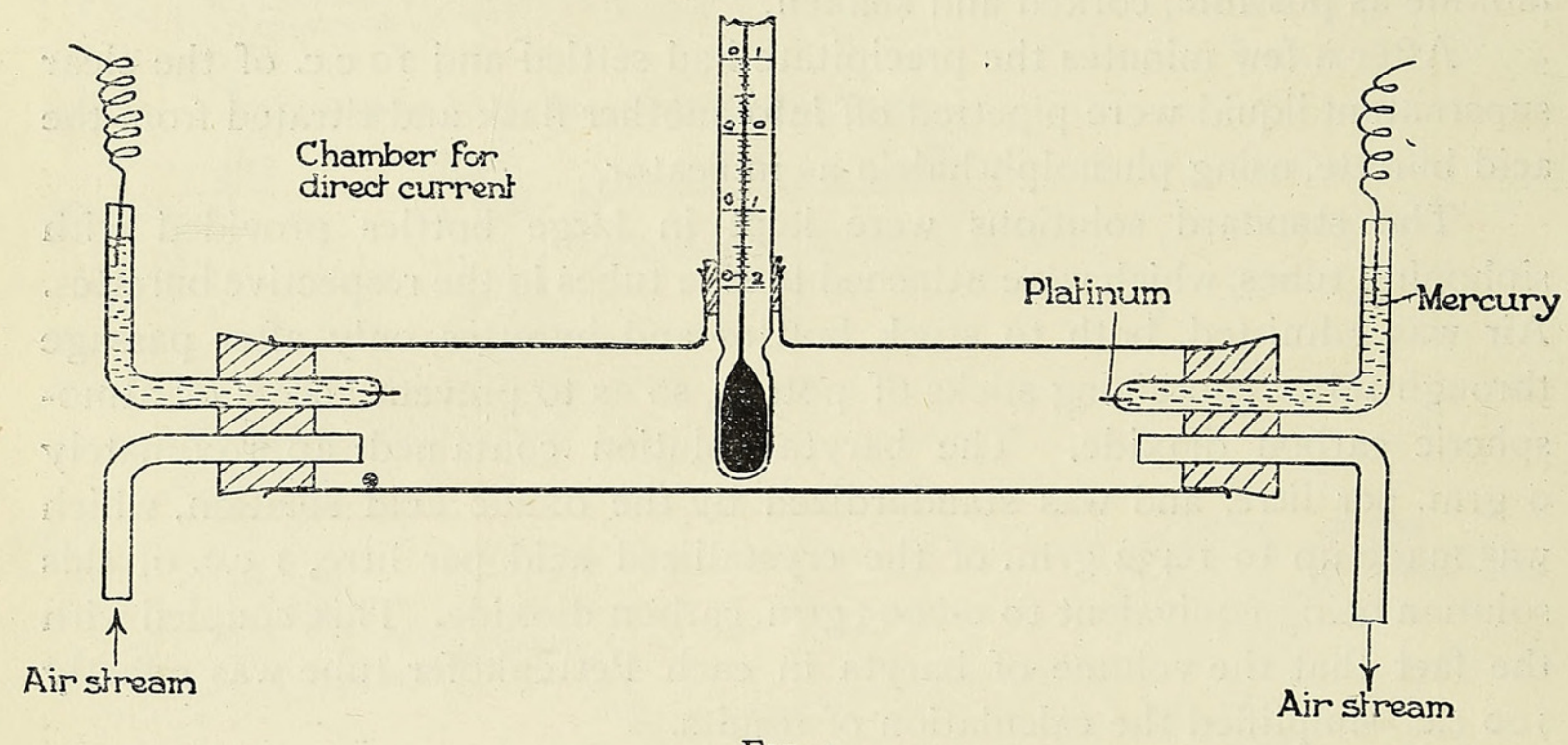

FIG. 2.

In all experiments the temperature was kept constant as far as possible, but slight variations were unavoidable. When these occurred, the carbon dioxide figure was corrected on the basis of the Van't Hoff law for chemical reactions, a rise of $10^{\circ} \mathrm{C}$. being considered to produce an increase of ioo per cent., all values being reduced to the temperature at which the first estimation was made. F. F. Blackman ${ }^{1}$ showed that respiration approximately followed this law, and we found that a control-curve obtained under varying temperature conditions, when corrected in this manner, became identical in form with the curve obtained from respiration at constant temperature.

Peas were used in the direct-current experiments, and the controlcurve was of the form shown in Fig. 3 (see also Table I).

For the sake of simplicity, a few typical results are introduced into the

1 Report of British Association, Dublin, I908, p. 896. 
text in each case, and an account of the repetitions of many of the experiments will be found in the Appendix.

In plotting the curves, each figure for carbon dioxide is attributed to the point of time terminating the period for which that value was obtained : thus in No. II 3 , Fig. 3 , the number 0.0100 represents the carbon dioxide output for the second half-hour and is plotted at time one hour.

The 'normal curve' of respiration, as represented by No. II3, Fig. 3, takes a decided downward trend from the beginning, its slope decreasing with time, until, about two hours from the start, the variations are reduced well below to per cent. This downward trend was observed in every

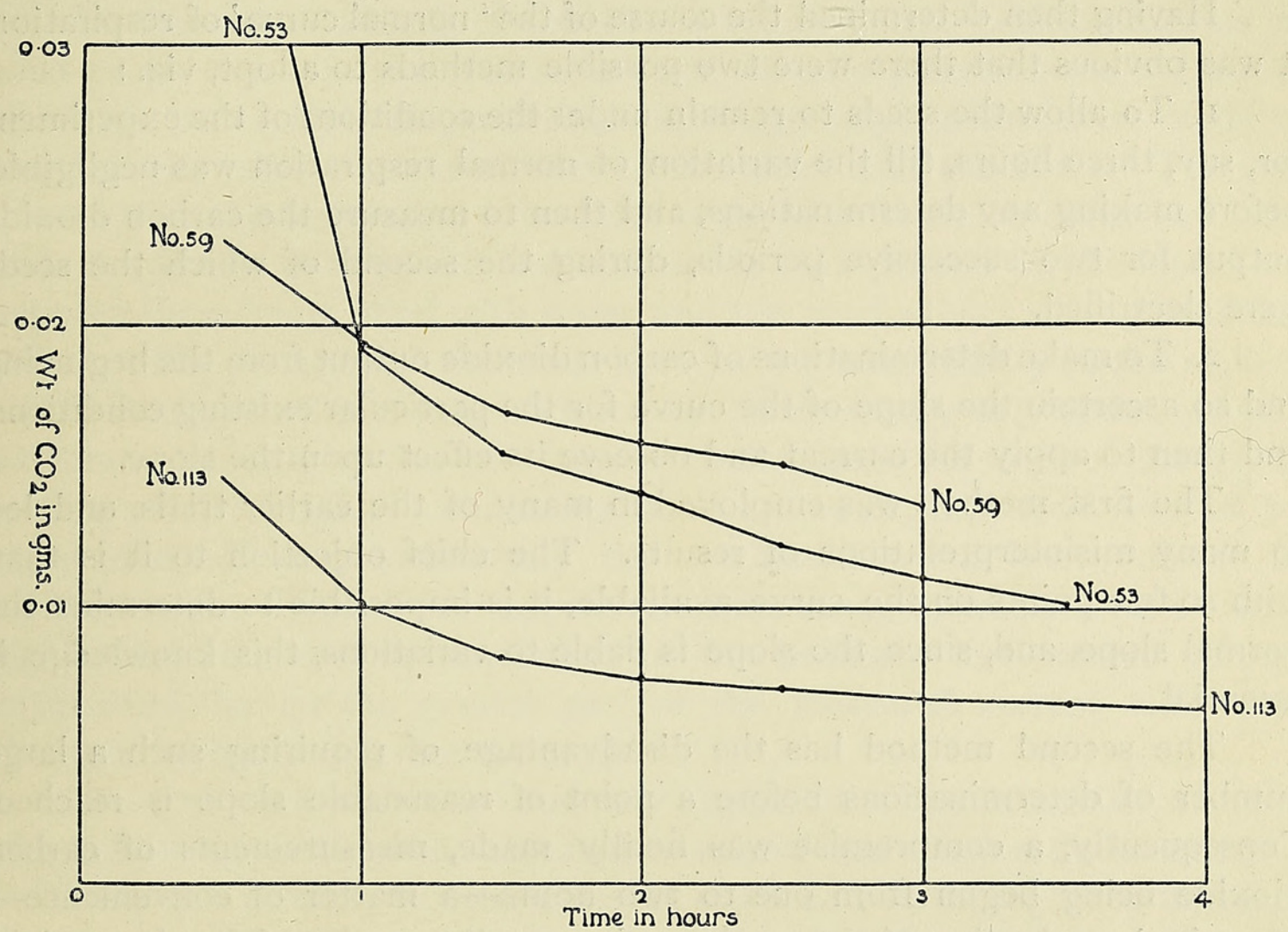

FIG. 3 .

control experiment carried out with germinating seeds, and is doubtless to be attributed to the fact that moisture is continually evaporating from the surface of the seeds, and owing to this loss of water the vital processes are retarded, the conditions gradually approaching the normal winter state, when respiratory functions are practically at a standstill.

It has been observed that slight alterations in the experimental conditions have a corresponding influence upon the shape of the curve, and it is perhaps advisable to enumerate these here.

The position of the first point of course depends primarily upon the number of seeds employed and the extent to which they have germinated.

The initial slope of the curve varies, as shown by a comparison of Nos. 53 and 59 , and this is probably due to the variation in the rate of 
evaporation, which in turn is caused by variations of initial temperature; but no trials have been carried out to substantiate this.

It will be seen that the curve of No. II 3 is quite regular, and the same applies to the controls enumerated later, but Nos. 53 and 59 show irregularities, amounting to not more than about 2 or 3 per cent., at the fourth and fifth point respectively. In view of the later experiments, there is no doubt that these irregularities are due to slight changes of temperature, since similar discrepancies appeared in No. II 3 and others before the temperature corrections were applied. Unfortunately, in the earlier experiments no record of temperature was obtained.

Having then determined the course of the 'normal curve' of respiration, it was obvious that there were two possible methods to adopt, viz.:

I. To allow the seeds to remain under the conditions of the experiment for, say, three hours, till the variation of normal respiration was negligible, before making any determinations, and then to measure the carbon dioxide output for two successive periods, during the second of which the seeds were electrified.

2. To make determinations of carbon dioxide output from the beginning and so ascertain the slope of the curve for the particular existing conditions, and then to apply the current and observe its effect upon the slope.

The first method was employed in many of the earlier trials, and led to many misinterpretations of results. The chief objection to it is that, with so few points on the curve available, it is impossible to determine the normal slope, and, since the slope is liable to variations, this knowledge is essential.

The second method has the disadvantage of requiring such a large number of determinations before a point of reasonable slope is reached. Consequently, a compromise was finally made, measurements of carbon dioxide being begun from one to two hours-a matter of convenienceafter the introduction of the seeds, and generally continued for six or eight successive periods, each of half an hour's duration, the current being applied during the fourth or fifth, whichever seemed more advisable.

Some thirty experiments were carried out in this manner, the current densities employed varying from about $10^{-6}$ amperes to more than $10^{-4}$ amperes, the intention being to imitate the current-conditions of the field trials (see Table II). In some of the early determinations it seemed as if the current had, indeed, produced an effect upon the evolution of carbon dioxide, but in the later ones, where temperature changes were accurately recorded, there was no deviation from the normal curve following the application of the current. The apparent effect referred to was evident in only a few cases, and its magnitude and even direction varied, and it is probable that it was due to unrecorded changes of temperature.

When the current density approached the upper limit there was a slight 
rise in the temperature of the seeds quite independent of the temperature changes of the laboratory, and this rise was found to correspond with that which was to be expected from a calculation from current strength. ${ }^{1}$

This rise of temperature has probably been an important factor in many of the results recorded in the field experiments, more especially where comparatively large direct currents through the soil have been employed. Löwenherz ${ }^{2}$ describes a rise of temperature observed in some experiments on the effect of direct currents upon the growth of barley, and suggests that the acceleration of growth which was recorded may have been due to this rise of temperature.

In the course of our direct-current experiments, doubts arose as to what proportions of the current measured actually passed through the peas and their water films respectively, and rough experiments were made to ascertain the relative conductivities of the water and the seeds. The conductivity of the respiration tube filled with water in which seeds had been soaked was first determined, and then seeds were packed in, the interstices between them being filled with water, and the conductivity was again determined. The presence of the seeds lowered the conductivity in the ratio of $2: \mathrm{I}$. Peas packed in a tube such as that used occupy only about one-half its volume, so that by the introduction of the seeds the area of the crosssection of the original conducting medium, water, has been reduced by about one-half, and incidentally the conductivity has been reduced in a similar ratio. From this it appears that the seeds themselves have a very high resistance, and consequently, in the ordinary low tension current experiment, by far the greater part of the measured current must pass through the water films on the seeds.

Thus we were unable to show any alteration of the katabolic processes of germinating seeds when subjected to minute low tension direct currents, but it was not possible to determine the exact current strengths in the seeds themselves. With low tension currents, then, unless the current is sufficiently strong to raise the temperature of the plant or its surroundings, no increase in the plant's respiration is to be expected. With high tension currents, no experiments have been carried out with currents greater than from $10-{ }^{13}$ to Io-11 amp. per sq. cm.; but no direct deductions can be drawn from this fact, as with the higher tension the distribution of the current in the plant may be very different.

\section{Experiments with High Tension Discharge.}

These trials were carried out chiefly with germinating peas, although a number of experiments were made upon seedlings. The method used was

1 But this calculation was based upon the formula for the heating effect of a current passing through a conductor. If the seeds behave as an electrolyte to the passage of the currents this calculation will not apply.

${ }^{2}$ Zeitschr. f. Pflanzenkrankheiten, vol. xviii, 1908, p. 336. 
identical with that described above, except in the form of the respiration chamber employed, which consisted of two bell-jars with ground flanges fitted together and rendered airtight with a vaseline-rubber composition. Each bell-jar was stoppered with a rubber stopper through which passed a delivery-tube and a platinum-mercury electrode. (See Fig. I.) The platinum wire of the lower electrode was attached to a disc of wire gauze on which the seeds rested, thereby ensuring good contact, whilst the mercury was ' earthed' by means of a wire connected to a water-pipe. The upper electrode was connected to the positive pole of the discharge apparatus by means of a rubber insulated cable running through quartz tubes borne on porcelain telegraph insulators.

The air-stream entered the chamber through the upper delivery-tube, and left it through the lower.

In the early experiments the source of electricity was a large influence machine kept running by a motor, but later the Lodge-Newman installation was used. This was much more satisfactory, the electrical output of the influence machine being very variable, and to some extent at the mercy of the weather.

It will be convenient to describe first the series of control experiments which were carried out under different conditions, as it is only in the light of these control experiments that experiments with the electric discharge can be interpreted.

I. Seeds were packed into the lower of the two bell-jars, and the curve of respiration determined as in the low tension current experiments, with the result that it was found impossible to depend upon obtaining a smooth normal curve every time. The irregularities were sometimes in onedirection and sometimes in another, and it was thought to be due to the fact that the close packing of the seeds prevented efficient aeration, the respiration being thus rendered partially anaerobic (Table III). In view of later observations, however, it seems likely that at least some of the irregularities were due to temperature variations, which were not recorded.

2. The seeds were separated from each other by layers of glass wool to ensure proper aeration, and the normal curve was again determined. The irregularities here were much less marked, and accordingly glass wool was always used in subsequent experiments (Table IV).

3. Electric discharge from a point in air causes the interaction of the gases of the air, with the formation of oxides of nitrogen and ozone, and probably, if water vapour is present, a little hydrogen peroxide.

Owing to misinterpretations of some of our results, coupled with some conclusions arrived at by Hill and Flack, ${ }^{1}$ who found that very small quantities of ozone were toxic to animals, it was thought that these gases had a deleterious effect upon the plants, and steps were taken to prevent 
them from reaching the living material. A small vessel of turpentine was introduced into the respiration chamber above the peas, which was found to be effective in absorbing the toxic gases. (See later experiments as to the effect of gases on seedlings.)

Since turpentine was used in many of the experiments, it became necessary to carry out controls with it, to ascertain its effect, if any, upon respiration. Accordingly the respiration curve was determined for peas separated by glass wool as in 2, with a vessel of turpentine in the respiration chamber, discharge not being applied.

The curve was found to coincide with the normal, the small amount of turpentine vapour which was unavoidably present in the atmosphere having no effect upon respiration (Table V).

4. The possibility of the decomposition of the turpentine by the discharge was next considered, and it was realized that if this took place, an evolution of carbon dioxide was a conceivable consequence, this being naturally undesirable, since carbon dioxide output was taken as a criterion of respiration.

To test this, a vessel of turpentine was placed in the respiration chamber, no seeds being present, and the discharge switched on, a stream of air being drawn through the whole apparatus as described above.

Analysis of the baryta solution in the Pettenkofer tube showed that no carbon dioxide had been evolved (Table VI).

Having completed these controls, full results of which will be found in the Appendix, experiments upon the effect of electrification upon the seeds were proceeded with.

When a platinum-mercury contact electrode was used to apply the discharge, it was found that under the conditions of experiment the current produced was very much in excess of that used in the field trials, and since our experiments were intended to be comparable with those trials, it was thought expedient to employ currents of the same order of magnitude. In order tocut down the voltage available with our apparatus, the following device was adopted and found effective. The tube of the electrode (see Fig. I) was filled with xylol instead of mercury, and the cable from the high tension installation rested in the xylol, which completed the contact with the platinum discharge point. By varying the length of the column of xylol between the ends of cable and platinum points, and thereby varying the resistance, it was possible to vary the current passing from the discharge point. ${ }^{1}$

When, however, this distance was below about I centimetre, a new factor became evident in the passing of sparks between the end of the cable and the platinum wire. The heat produced caused the xylol finally to boil, and it became necessary to switch off the discharge. Another disadvantage

1 See N. R. Campbell, Phil. Mag., Ser. vi, vol. 22, p. 30 I, Appendix to paper on Delta Rays. 
of the short xylol resistance is the fact that sparks are liable to penetrate the glass tube and pass down the side of the respiration chamber, incidentally allowing the xylol to escape on to the seeds. Although quartz electrodes were tried instead of glass ones, this difficulty was never entirely obviated. A series of experiments was carried out using different current densities, but owing to the obstacle mentioned we were unable to get any current densities above $3 \times 10^{-6}$ amperes, except that obtained with a mercuryplatinum contact electrode, namely about 5 or $6 \times 10^{-6}$ amperes.

The method of procedure in these discharge trials was the same as that described for the direct-current experiments, i. e. the seeds were introduced into the respiration vessel and maintained under normal conditions for a time, determinations of carbon dioxide output being made every halfhour. These values gave an indication of the trend of the normal curve for the particular set of seeds under observation, and the discharge was switched

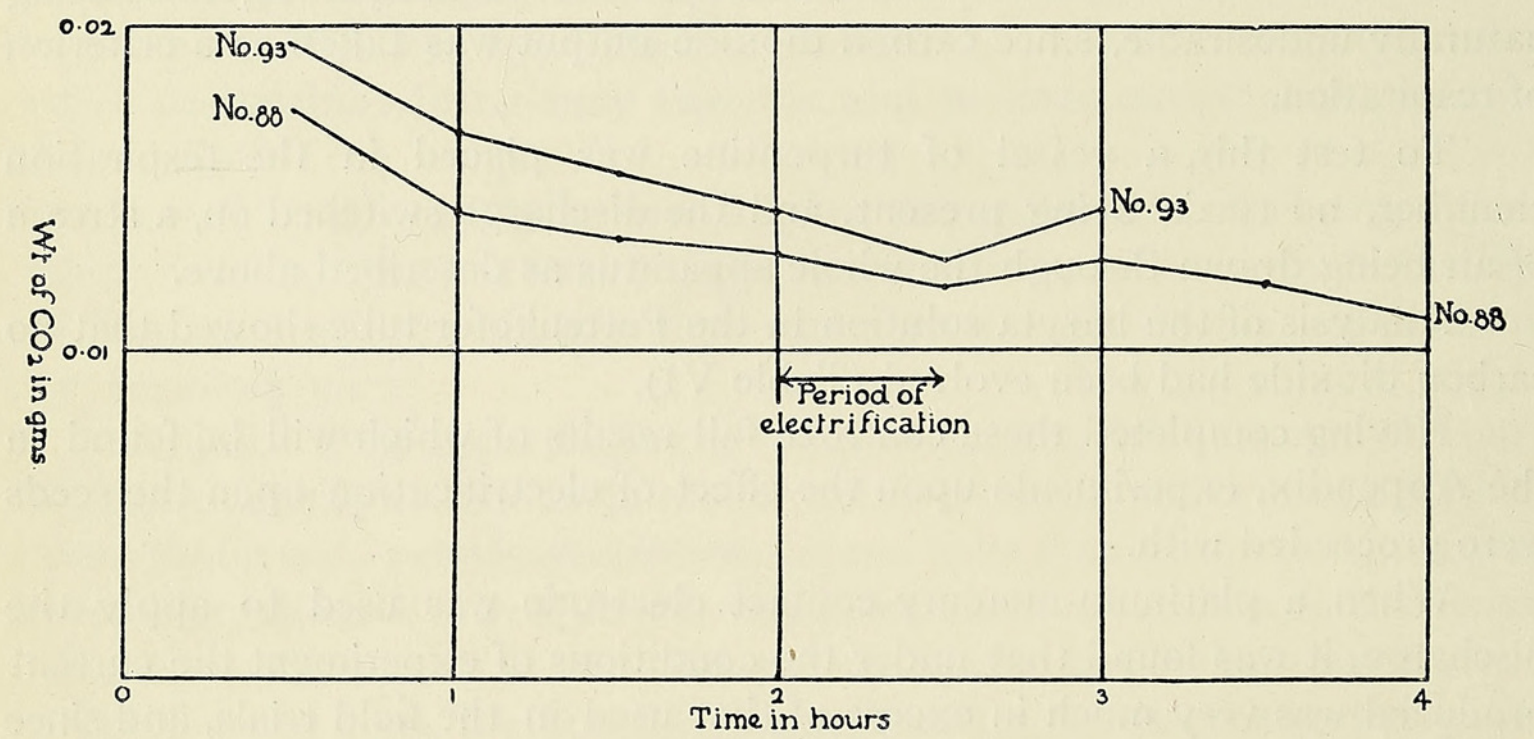

FIG. 4 .

on usually during the fifth half-hour from the start, two or three determinations being made after the return to the unelectrified condition.

The results of these experiments are given in full in the Appendix, and it will be seen that discharge producing a current density of less than about $3 \times 10^{-6}$ amperes has no effect upon the respiration of the seeds, the normal curve being uninterrupted at any point. When, however, a current density of $3 \times 10^{-6}$ amperes was reached there was a definite irregularity in the curve (see Fig. 4). The irregularity consists of a rise which takes place, not during the period of electrification, but during the half-hour following it. Sometimes the rise is very slight, and in one case (No. 90) there was no actual rise, but the slope of the curve was diminished, indicating that the carbon dioxide output was nevertheless greater, consequent upon electrification, than it otherwise would have been. The magnitude of this general 
accelerating effect of the discharge seemed to bear a definite relation to the current strength (Tables VII and VIII).

Having demonstrated that the application of overhead discharge caused an increase in the respiration of the seeds, it became necessary to analyse further the cause of the increase.

The first source investigated was the gases produced by the discharge in air, as it was thought these might have some effect upon the katabolic processes of the plant. This was investigated in the following manner:

Two pairs of bell-jars were fitted up as respiration chambers and connected in series in the apparatus. The first was left empty except for an earthed piece of wire about half-way down, where the upper level of the mass of seeds would ordinarily be. The second chamber contained the seeds and had no electrodes and no turpentine, but merely delivery-tubes.

The discharge now took place in the first chamber, and the gases were led into the second. In this way there was much less chance of ions from the discharge point reaching the peas.

With this method the respiration was found to be unaffected by the discharge, and the curves show no deviation from the normal (Table IX) except in one reading, No. I2I. 4, the significance of which is doubtful. (See note re temperature corrections, p. 145.)

We concluded, therefore, that the gaseous products of the discharge in air had no effect upon the respiration of seeds, which was rather surprising in view of the results of Hill and Flack working with ozone. The source of the effect produced by the discharge must therefore be sought in another direction.

Experiments were carried out in which the period of electrification was extended from half an hour to three hours (Nos. 96-8), and the usual increase in carbon dioxide output was observed, but on dismantling the apparatus at the conclusion it was noticed that the temperature of the chamber was very much above that of the room ; especially was this the case in No. 97, in which the amount of respiration was enormously increased (see Fig. 5). Attention was at once directed to the influence which this rise of temperature might have when the discharge was continued for only half an hour.

Accordingly a trial was proceeded with (No. 98), wherein the temperature of the seeds was taken from time to time by a thermometer inside the chamber. The discharge was switched on for one hour, and determinations of carbon dioxide were made every half-hour. By this means the curve (No. 98) in Figs. 5 and 6 was obtained. This curve was then subjected to two tests to determine to what extent temperature was the active factor in inducing the upward trend. The figures obtained were corrected in the manner indicated for the direct-current experiments (p. I42) and the new curve (Fig. 6) compared with the normal curve and No. 98.

The corrected curve, it will be seen, almost coincides with the normal curve. 
A series of experiments was carried out in this manner, the corrected curves showing a similar coincidence with the normal curve (Table XI). It should be noted here, and the same applies to all temperature corrections, that such corrections can only be regarded as approximate owing to the difficulty of making accurate determinations of temperature.

The rate of conduction of heat through peas is very slow, and in some extreme cases it was observed that after electrification there was a difference of temperature between the highest and lowest level of seeds of $6^{\circ} \mathrm{C}$. This is liable to increase the possible error of temperature readings, which, in order to be consistent, were always taken with the thermometer bulb just covered with seeds, and readings were taken as often as convenient, viz. at intervals of five or ten minutes.

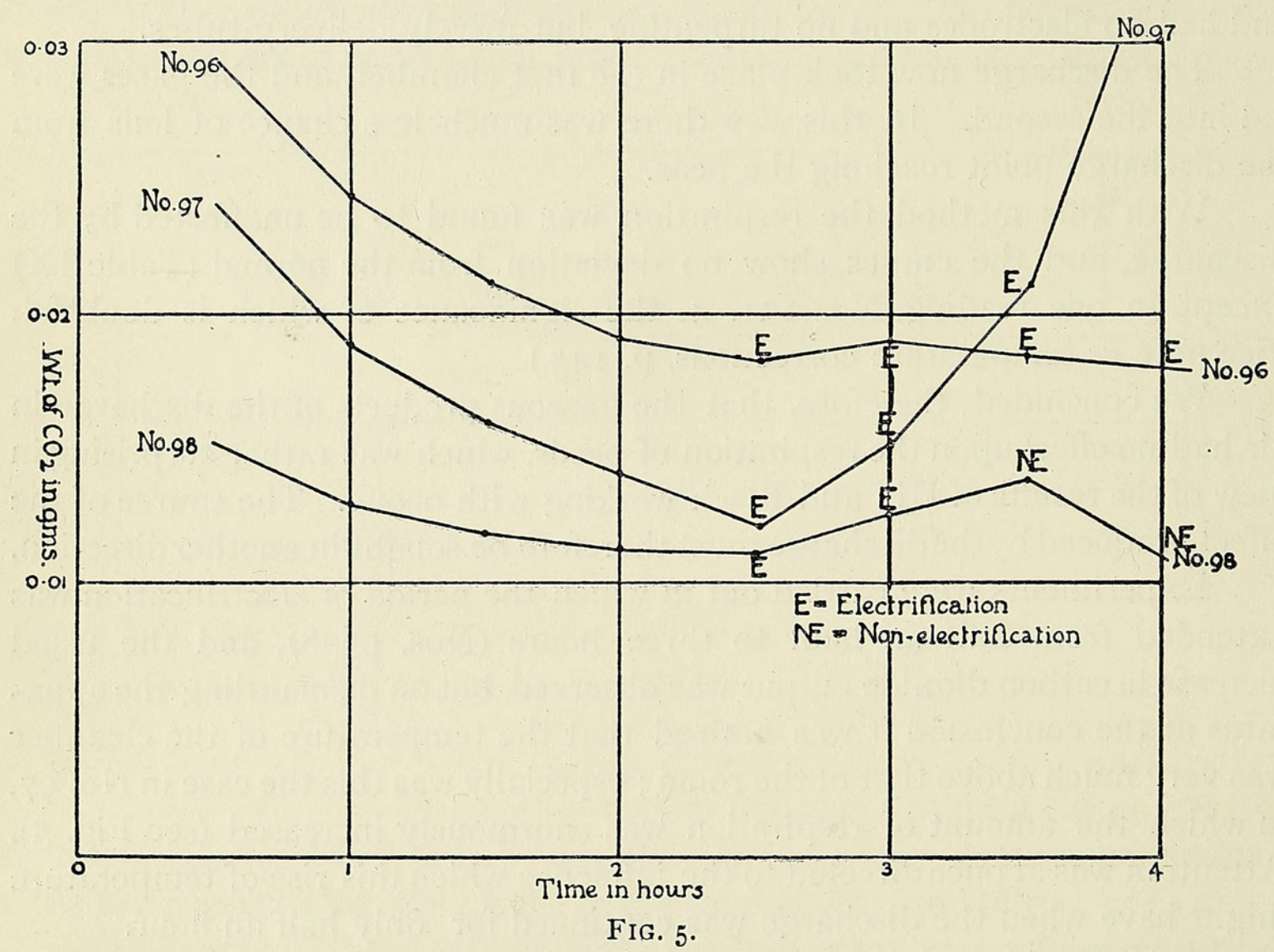

This inaccuracy probably accounts for the fact that the corrected curve mentioned above is not quite smooth, as a normal curve should be.

Steps were now taken to ascertain if, as the form of the corrected curve seemed to suggest, when temperature effects were eliminated, the effect of the discharge upon respiration was also eliminated.

This was first attempted in an indirect manner thus :

The respiration chamber was immersed in a large water-bath, and instead of applying the discharge, the temperature was regulated by means of the bath, and was made to vary to the same extent and at the same intervals as in No. 98. 
By this means all effects of the discharge, other than those caused by temperature changes, would be eliminated, and any discrepancies between the curve obtained in this case and that in No. 98 would be due to stimuli other than a rise of temperature.

In this experiment (No. 99) the curve obtained was almost exactly parallel to that obtained in No. $9^{8}$ (see Fig. 6). The only divergence appeared at the last two points, and during these periods the temperature of the water-bath, and consequently that of the seeds, did not correspond exactly to the readings in No. 99. When these two are corrected the discrepancy is even less (Table XII).

Thus the whole effect of the discharge recorded in No. $9^{8}$ was obtained merely by altering the temperature and in the absence of any other effects of the discharge.

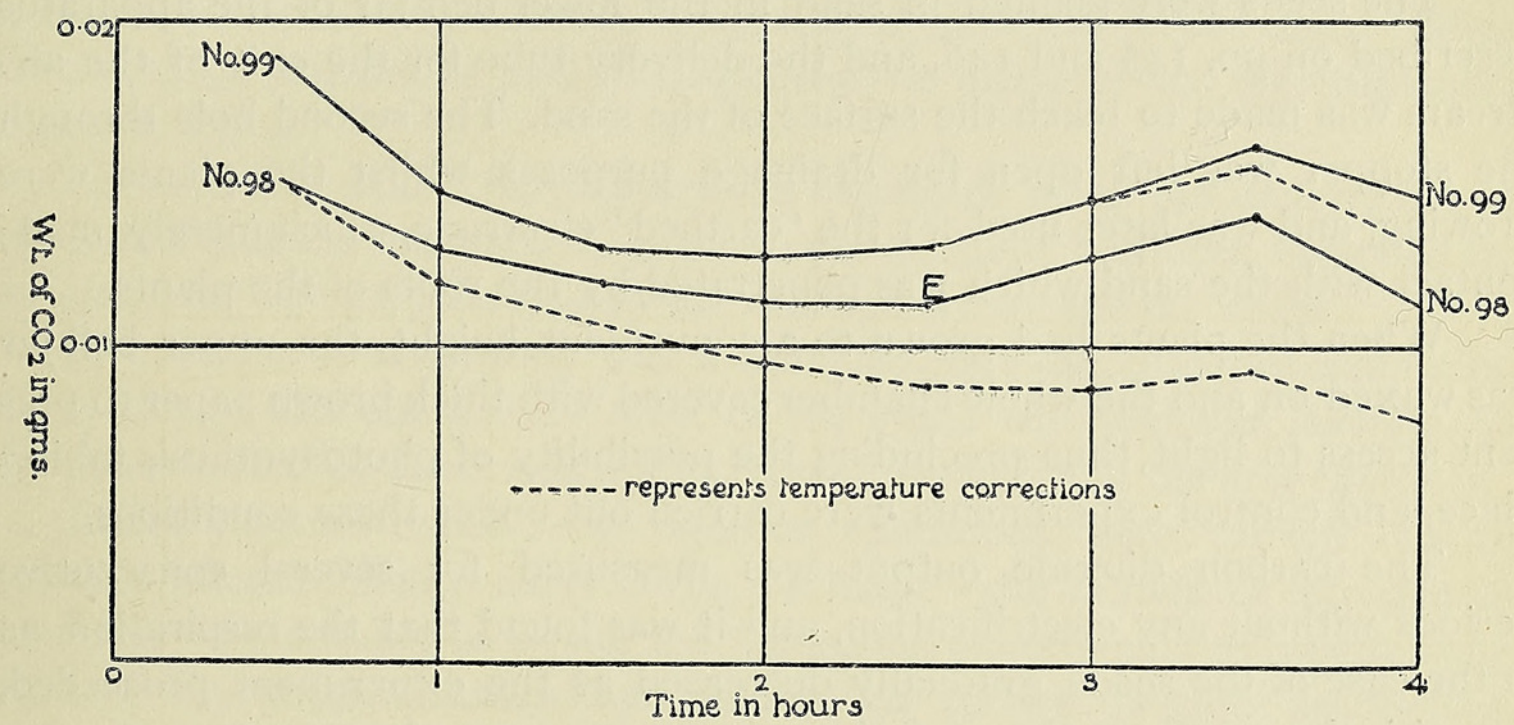

FIG. 6 .

Attempts were now made directly to eliminate the effects of temperature by keeping the seeds at a constant temperature during electrification. Three methods were adopted (Table XIII):

I. The respiration chamber was immersed in a water-bath, the temperature of which was lowered as that of the seeds tended to rise under the influence of the discharge. This was found impracticable, owing to the low thermal conductivity of the peas (No. I03).

2. A thick layer of glass wool was superposed upon the seeds to absorb the heat evolved, but this was quite ineffectual (No. 104).

3. The glass-wool layer was supplemented with a layer of peas previously killed by prolonged boiling, but this also failed to keep the temperature of the live peas at a constant level (No. 105).

Thus we were unfortunately unable directly to eliminate the effects of temperature from the experiments, with a discharge producing relatively high currents. 
A suggestion presented itself to the effect that the rise of temperature so constantly observed might be the result, and not the cause of the acceleration of the katabolic processes accompanying it, but this explanation was confuted by experiments upon the electrification of dead peas (Table XIV). In this case it was found that there was again a rise of temperature, whereas there was certainly no acceleration of the katabolic processes, the conclusion being that the increased carbon dioxide output in the experiments upon living seeds was indeed due to the temperature rise.

Some experiments were also carried out upon the effect of the electric discharge upon the respiration of seedlings. The plants used included peas, brussels sprouts, wheat, and rye, the two last proving the more satisfactory, on account of their more rapid germination and larger evolution of carbon dioxide per unit space occupied.

The seeds were planted in sand in the lower bell-jar of the apparatus described on pp. 145 and I 46 , and the delivery-tube for the exit of the airstream was made to reach the surface of the sand. The second hole through the stopper was left open for drainage purposes whilst the plants were growing, and was later used for the 'earthed' electrode, which merely made contact with the sand which was penetrated by the roots of the plants.

When the plants had grown to a convenient height, the upper bell-jar was waxed on and the whole chamber covered with thick brown paper to prevent access to light, thus precluding the possibility of photosynthesis taking place, and control experiments were carried out under these conditions.

The carbon dioxide output was measured for several consecutive periods without any electrification, and it was found that the respiration, as in the case of the seeds, gradually decreased as the experiment proceeded, but with the seedlings the variation was never more than 5 per cent. after corrections had been made as usual to compensate for temperature changes (Table XV).

Accordingly, instead of finding a normal curve in each experiment, as in the case of seeds, it was considered permissible to measure the carbon dioxide evolved during two successive periods, the discharge being switched on at the beginning of the second. The length of each period was usually one hour, sometimes two, a convenient quantity of carbon dioxide being produced in this time. In the results, differences of less than 5 per cent. were disregarded as insignificant in view of the information obtained from controls.

A series of experiments was carried out under these conditions, employing current densities up to $10^{-6}$ amperes, which were obtained by means of the xylol resistance previously described. Above this strength no results were obtained, owing to the failure of the xylol to withstand the heat produced (see p. I47).

In no case was it possible to record any significant variation of the 
amount of carbon dioxide produced consequent upon the application of the discharge, the differences being always less than 5 per cent. (Table XVI).

Experiments with discharge from a mercury-platinum contact electrode, giving a current density of 3 to $6 \times 10^{-6}$ amperes, were attempted, but no quantitative observations were made owing to the tendency of sparks to pass from the discharge wire to the plants, thereby causing them to shrivel.

The effect of the gaseous products of the discharge in air upon seedlings was then tested, the method being identical with that used for similar tests with seeds (p. I49).

The discharge in the first chamber was maintained for periods varying from five minutes to two hours, the products being drawn into the second chamber containing the seedlings.

The result was a rather unexpected one, namely, an apparent increase in the carbon dioxide produced, in one case a matter of 67 per cent. When the discharge was on for only five minutes the increase was inconsiderable (Table XVII).

In addition, when the plants were examined after the experiment, it was found that the chlorophyll in the upper portions had been bleached by the oxidizing agents produced in the atmosphere by the discharge.

If a vessel of turpentine was introduced into the chamber containing the seedlings, the deleterious effect of the gases was obviated, leaving the plants unaffected by continued application of discharge in the first chamber.

Some controls under very rigorous conditions were carried out to ascertain whether the products of the discharge - the oxides of nitrogen in particular-were liable to vitiate the foregoing experiments by neutralizing some of the baryta solution independent of carbon dioxide production. Accordingly the products of discharge in an empty chamber were led (I) directly through baryta solution in a Pettenkofer; (2) through a chamber containing dead peas, and then through baryta solution. The period in each case was thirty minutes, and the current density was approximately $6 \times 10^{-5}$ amperes, the highest employed in any experiments.

The result showed a maximum production of acid equivalent to $0.00 \mathrm{II}$ grm. carbon dioxide in the case where the gases were led directly through the alkali. Where peas intervened-the normal case-the carbon dioxide equivalent was $0.0002 \mathrm{grm}$. (Table X).

Thus in the experiments upon the effect of the products of discharge upon seedlings the apparent increase in the amount of carbon dioxide evolved was probably due to the acidity of the oxides of nitrogen present, but in the experiments with seeds these gases were absorbed before reaching the baryta solution.

As a result of this work we have reached the conclusion that the electric discharge has no direct effect upon the respiration of germinating seeds and seedlings, but under laboratory conditions, wherein the plants are in a 
confined space, the heating effect of the discharge may provide a stimulus causing an acceleration of the katabolic processes and a consequent increase in the carbon dioxide production.

The failure of the discharge itself to produce any stimulation of the destructive metabolism of the organism should not, however, be emphasized overmuch when seeking an explanation of the results of the large scale trials. As has been pointed out before, although these results cannot be interpreted in terms of katabolism, other functions of the plants may be accelerated as a consequence of electrification, resulting finally in earlier maturity.

In view of the nature of our conclusions there is little to be said as to their application to field trials.

With the current density employed in the field $-10^{-12}$ to $10^{-10}$ amperes per square centimetre-the heating effect will certainly be negligible, and the effect upon respiration therefore nil. In addition, were the heating effect, and no other, involved, there would be no economic value in applying electric discharge in order to obtain it, since the same result might be arrived at by much less elaborate methods. This, however, is a question upon which no final judgement can be passed until the reported acceleration effect in the field has been further analysed.

\section{SUMMARY.}

I. Field trials upon the effect of electrical conditions upon plant growth have suggested that an increased crop or an earlier ripening may be the result of such treatment, and in the present paper an attempt has been made to analyse this apparent effect, by determining the effect of such electrical conditions upon respiration.

2. Our experiments have shown that direct currents of a density $10^{-6}$ to $10^{-4}$ amperes have no effect upon the respiration of peas, other than that due to accompanying changes of temperature. The proportion of these currents actually traversing the peas was, however, probably very small, the majority being taken by the water films on the seeds.

3. Overhead discharge, producing a current of density less than $3 \times 10^{-6}$ amperes, has no effect upon respiration. When higher currents are employed a definite increase of the carbon dioxide output was observed.

4. This increase can be wholly attributed to the rise of temperature caused by the discharge.

5. In the field, where the currents are too small to produce any appreciable rise of temperature, electrification will have no effect upon respiration, and explanation of the acceleration of growth must be sought in other functions of the plant.

6. The gaseous products of the discharge in air have no effect upon germinating peas, but are deleterious to young seedlings. 


\section{APPENDIX.}

This portion of the paper consists of a detailed account of some of the experiments carried out, including repetitions. Reference to these has been made in the foregoing pages, and typical experiments have been quoted.

Full discussion has already been entered upon, and therefore only necessary explanations accompany the following figures.

The numbers, unless otherwise stated, represent the weight of carbon dioxide in grammes.

Experiments marked * are those in which corrections have been made for temperature differences, and only the corrected numbers given.

E represents a period of electrification, and a bracketed number following it the current density in amperes. Where none is given, no measurement was made.

Table I. Controls with Chamber used for Direct Current Experiments (p. I 43).

Experi

53
0.0381
0.0191
0.0153
0.0139
0.0121
0.0108
0.0099
-

59

0.0229

0.0192

0.0168

0.0157

0.0148

0.0134

二

$113^{*}$
0.0146
0.0100
0.0081
0.0073
0.0069
0.0066
0.0064
0.0062

I $3^{*}$

0.0146

0.0100

0.0073

0.0069

0.0064

0.0062

N.B.-The number of experiments here is small, but was considered sufficient owing to the fact that the conditions were almost identical with those in the control experiments with the chamber for discharge upon seeds (Table IV).

\section{Table II. Effect of Direct Current on Peas:}

Experiment No.
Estimation $N o$.

$\begin{array}{cc}\text { riment No. } & 54 \\ \text { I } & 0.0402 \\ 2 & 0.0283 \\ 3 & 0.0236 \\ 4 & 0.0220 \mathrm{E} \\ & \left(0.3 \times 10^{-6}\right) \\ 5 & 0.017 \mathrm{I} \\ 6 & 0.0154 \\ 7 & 0.0135 \\ 8 & -\end{array}$

Experiment No.

Estimation No.

I
2
3
4

5
6
7

55
0.0360
0.0304
0.0264
$0.0222 \mathrm{E}$
$\left(0.6 \times 10^{-6}\right)$
0.0176
0.0158
0.0125

\section{Continued.}

$\begin{array}{cc}65 & 63 \\ 0.0350 & 0.0273 \\ 0.0227 & 0.0202 \\ 0.0182 & 0.0187 \\ 0.0143 \mathrm{E} & 0.0144 \mathrm{E} \\ \left(5.8 \times 10^{-6}\right) & \left(6 \times 10^{-6}\right) \\ 0.0134 & 0.0140 \\ 0.0117 & 0.013 \mathrm{I} \\ 0.009 \mathrm{I} & 0.0127\end{array}$

\section{$5^{6}$}

$$
0.0349
$$$$
0.0225
$$$$
0 . \overline{01} 54
$$

0.0127

$\frac{0.0113 \mathrm{E}}{\left(0.5 \times 10^{-6}\right)}$

0.0106

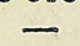

\section{7}

0.0494
0.0288
0.0156
$0.0119 \mathrm{E}$
$\left(0.5 \times 10^{-6}\right)$
0.0090
0.0092
-

62

64
0.0236
0.0180
0.0157
$0.0145 \mathrm{E}$
$\left(6 \times 10^{-6}\right)$
0.0113
0.0119

0.0344
0.0290
0.0252
$0.0189 \mathrm{E}$
$\left(6.5 \times 10^{-6}\right)$
0.0157
0.0117
0.0089

66

58

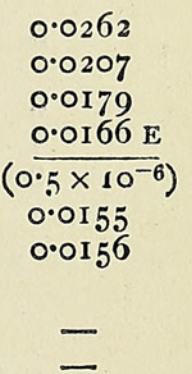

0.0234

0.0184

0.0162

$\frac{0.0134 \mathrm{E}}{\left(7.4 \times 10^{-6}\right)}$

0.0115

0.0101

0.0090 
TABLE II. Continued.

\begin{tabular}{|c|c|c|c|c|c|}
\hline $\begin{array}{l}\text { Experiment No. } \\
\text { Estimation No. }\end{array}$ & 68 & 67 & $6 I$ & 69 & 70 \\
\hline I & 0.0478 & 0.0504 & 0.0347 & 0.0346 & 0.0347 \\
\hline 2 & 0.0403 & 0.04 I 5 & 0.0284 & 0.0279 & 0.0266 \\
\hline 3 & 0.0327 & 0.0362 & 0.0250 & 0.0250 & 0.0222 \\
\hline 4 & 0.0260 & 0.0316 & $\frac{0.0219 \mathrm{E}}{\left(17.6 \times 10^{-6}\right)}$ & 0.0230 & 0.0197 \\
\hline 5 & 0.0212 & $\frac{0.0275 \mathrm{E}}{\left(15.1 \times 10^{-6}\right)}$ & 0.0186 & $\frac{0.0206 \mathrm{E}}{\left(20.4 \times 10^{-6}\right)}$ & $\frac{0.0181 \mathrm{E}}{\left(20.6 \times 10^{-6}\right)}$ \\
\hline 6 & $\frac{0.0188 \mathrm{E}}{\left(13.9 \times 10^{-6}\right)}$ & 0.0249 & 0.0159 & 0.0178 & 0.0162 \\
\hline $\begin{array}{l}7 \\
8\end{array}$ & $\begin{array}{l}0.0170 \\
0.0143\end{array}$ & $0.022 I$ & 0.0143 & $0 . \overline{0168}$ & $\begin{array}{l}0.0144 \\
0.0128\end{array}$ \\
\hline
\end{tabular}

\section{Continued.}

\begin{tabular}{|c|c|c|c|c|c|}
\hline Experiment No. & 60 & $7 I$ & 72 & 73 & 74 \\
\hline I & 0.0250 & 0.0188 & 0.0190 & 0.0375 & 0.0246 \\
\hline 2 & 0.0202 & 0.0162 & 0.0155 & 0.0258 & $0.02 \mathrm{I}_{4}$ \\
\hline 3 & 0.0177 & 0.0134 & 0.0126 & $0.02 \mathrm{I}_{4}$ & 0.0183 \\
\hline 4 & 0.0159 & 0.0118 & 0.0105 & 0.0186 & 0.0160 \\
\hline 5 & $0.0148 \mathrm{E}$ & $0.0095 \mathrm{E}$ & $0.0087 \mathrm{E}$ & $0.0164 \mathrm{E}$ & $0.0130 \mathrm{E}$ \\
\hline & $\left(\overline{24 \times 10^{-6}}\right)$ & $\left(\overline{25 \times 10^{-6}}\right)$ & $\left(\overline{30 \times 10^{-6}}\right)$ & $\left(\overline{47 \cdot 3 \times 10^{-6}}\right)$ & $\left(\overline{50 \cdot 5 \times 10^{-6}}\right)$ \\
\hline 6 & $0.014 I$ & 0.0085 & 0.0083 & 0.0152 & O.0I I9 \\
\hline 7 & - & 0.0078 & 0.0075 & 0.0140 & 0.0101 \\
\hline 8 & - & 0.0070 & - & 0.0135 & 0.0094 \\
\hline
\end{tabular}

\section{Continued.}

\begin{tabular}{|c|c|c|c|c|c|}
\hline Experiment No. & 75 & 76 & 77 & 78 & 79 \\
\hline I & 0.0277 & 0.0145 & 0.0369 & $0.028 \mathrm{I}$ & $0.026_{4}$ \\
\hline 2 & 0.0233 & 0.0105 & 0.0243 & 0.0209 & 0.0188 \\
\hline 3 & 0.0199 & 0.0094 & 0.0203 & 0.0186 & $0.016 \mathrm{I}$ \\
\hline 4 & 0.0169 & $\frac{0.0088 \mathrm{E}}{\left(75^{.6 \times 10^{-6}}\right)}$ & 0.0174 & 0.0160 & 0.0153 \\
\hline 5 & $\frac{0.0151 \mathrm{E}}{\left(67 \times 10^{-6}\right)}$ & 0.0078 & $\frac{0.014 .3 \mathrm{E}}{\left(80.4 \times 10^{-6}\right)}$ & $\frac{0.0140 \mathrm{E}}{\left(83.1 \times 10^{-6}\right)}$ & $\left.\frac{0.013 .3 \mathrm{E}}{\left(96.4 \times 10^{-6}\right.}\right)$ \\
\hline 6 & $0.014 \mathrm{I}$ & 0.0072 & 0.0126 & $0.013^{2}$ & $0.013^{2}$ \\
\hline 7 & $0.013^{2}$ & 0.0070 & 0.0122 & 0.0129 & 0.0121 \\
\hline
\end{tabular}

\section{Continued.}

\begin{tabular}{|c|c|c|c|c|}
\hline Experiment No. & $116^{*}$ & I I $7^{*}$ & I I $4^{*}$ & I I $5^{*}$ \\
\hline 1 & 0.0149 & 0.0168 & 0.0166 & 0.0115 \\
\hline 2 & - & 0.0129 & 0.0139 & 0.0094 \\
\hline 3 & 0.0096 & O.OIII & 0.0112 & 0.0076 \\
\hline 4 & 0.0088 & 0.0097 & 0.0091 & 0.0070 \\
\hline 5 & $0.0086 \mathrm{E}$ & $0.0084 \mathrm{E}$ & 0.009 I E & $0.0077 \mathrm{E}$ \\
\hline $\begin{array}{l}6 \\
7 \\
8\end{array}$ & $\begin{array}{c}\left(135.8 \times 10^{-6}\right) \\
0.0078 \\
0.0076 \\
0.0069\end{array}$ & $\begin{array}{c}\left(14 \overline{5.5 \times 10^{-6}}\right) \\
0.0076 \\
0.0068 \\
0.0065\end{array}$ & $\begin{array}{c}\left(149.8 \times 10^{-6}\right) \\
0.0084 \\
0.0067 \\
0.0063\end{array}$ & $\begin{array}{c}\left(15 \overline{1 \cdot 2 \times 10^{-6}}\right) \\
0.0084 \\
0.0089 \\
0.0094\end{array}$ \\
\hline
\end{tabular}

In No. 115 the temperature variations were very considerable, $3^{\circ} \mathrm{C}$, and the corrections are therefore probably not to be considered accurate. 
Table III. Controls with Chamber for Discharge Methods. Peas not Separated by Glass Wool.

Experiment No. I

Estimation No.

$\begin{array}{ll}1 & 0.0369 \\ 2 & 0.0371 \\ 3 & 0.0437 \\ 4 & 00332 \\ 5 & 0.0289 \\ 6 & 0.0385\end{array}$

Experiment No. Estimation No.

I
2
3
4
5
6
7
8
9

2
0.0600
0.0612
0.0683
0.0505
0.0519
-

3
0.0161
0.0281
0.0275
0.0245
0.0238
0.0229

4
0.0226
0.0348
0.0331
0.0259
0.0244
0.0237

5

$\begin{array}{ll}0.0169 & 0.0227 \\ 0.0262 & 0.0316 \\ 0.0261 & 0.0278 \\ 0.0223 & 0.0255 \\ 0.0223 & 0.0247 \\ 0.0226 & 0.0228\end{array}$

Continued.

\section{8}

$\begin{array}{cc}0.0107 & 0.0106 \\ 0.0275 & 0.0114 \\ 0.0182 & 0.0121 \\ 0.0159 & 0.0124 \\ 0.0156 & 0.0103 \\ 0.0178 & 0.0113 \\ - & - \\ - & -\end{array}$

$\begin{array}{cc}9 & 10 \\ 0.0226 & 0.0140 \\ 0.0348 & 0.0118 \\ 0.0331 & 0.0105 \\ 0.0259 & 0.0100 \\ 0.0244 & 0.0097 \\ 0.0237 & 0.0094 \\ - & 0.0109 \\ - & 0.0104 \\ - & -\end{array}$

$\begin{array}{cc}\text { I I } & \text { I 2 } \\ 0.0165 & 0.0086 \\ 0.0215 & 0.013 \text { I } \\ 0.0200 & 0.0106 \\ 0.0181 & 0.0107 \\ 0.0174 & 0.0108 \\ 0.0174 & 0.0096 \\ 0.0180 & 0.0096 \\ 0.0162 & 0.0083 \\ 0.0184 & 0.0089\end{array}$

Table IV. Controls with Chamber for Discharge Methods. Peas separated by Glass Wool. No Electrification.

\begin{tabular}{|c|c|c|c|c|}
\hline Experiment No. & I3 & I4 & I 5 & I6 \\
\hline I & 0.0337 & 0.0347 & -(?) & 0.0608 \\
\hline 2 & 0.0319 & 0.0317 & - (?) & $0.044^{6}$ \\
\hline 3 & 0.0307 & 0.0278 & 0.0416 & $0.03^{6} 3$ \\
\hline 4 & 0.0295 & 0.0237 & 0.0369 & 0.0287 \\
\hline 5 & $0.029^{2}$ & 0.0223 & 0.0349 & 0.0227 \\
\hline 6 & $0.028 \mathrm{I}$ & 0.0194 & 0.0304 & 0.0208 \\
\hline 7 & - & 0.0179 & 0.0296 & 0.0187 \\
\hline 8 & - & 0.0158 & 0.0279 & 0.0172 \\
\hline 9 & 一 & 0.0136 & 0.0264 & 0.0155 \\
\hline Io & - & - & 0.0250 & 0.0140 \\
\hline I I & - & 一 & $0.024 I$ & 0.0125 \\
\hline 12 & - & - & 0.0227 & 一 \\
\hline 13 & - & - & 0.0213 & - \\
\hline
\end{tabular}

Table V. Controls with Chamber for Discharge Methods. Vessel of Turpentine within. Seeds Separated by Glass Wool.

$\begin{array}{cccccc}\begin{array}{c}\text { Experiment No. } \\ \text { Estimation No. }\end{array} & \text { I } & 18 & \text { I } & 20 & \text { I36 } \\ \text { I } & - & 0.0423 & 0.0549 & 0.0420 & 0.0299 \\ 2 & 0.0152 & 0.0389 & 0.0494 & 0.0355 & 0.0276 \\ 3 & - & 0.0331 & 0.0399 & 0.0317 & 0.0239 \\ 4 & - & 0.0275 & 0.0336 & 0.0261 & 0.0195 \\ 5 & 0.0148 & 0.0239 & 0.0282 & 0.0228 & 0.0165 \\ 6 & 0.0140 & 0.0215 & 0.0242 & 0.019 \mathrm{I} & 0.0138 \\ 7 & 0.0135 & 0.0195 & 0.0235 & 0.017 \mathrm{I} & 0.0126 \\ 8 & 0.0132 & 0.0191 & 0.0216 & 0.0165 & - \\ 9 & 0.0117 & 0.0185 & 0.0208 & - & - \\ 10 & - & 0.0181 & 0.0185 & - & - \\ \text { II } & - & 0.0177 & - & - & - \\ 12 & - & 0.0173 & - & - & -\end{array}$




\section{I58 Knight and Priestley.-The Respiration of Plants}

\section{Table VI. Controls. Electrical Discharge upon Turpentine. No Seeds PRESENT.}

The figures represent the volume of standard oxalic acid solution required to neutralize Io c.c. of the baryta solution after the passage of the air current.

$\begin{array}{cccc}\text { Experiment No. } & 23 & 24 & 26 \\ \begin{array}{c}\text { Estimation No. } \\ \text { I }\end{array} & 23.59 & 23.52 & \frac{23.00 \mathrm{E}}{23 . \mathrm{I} 2} \\ 2 & \frac{23.6 \mathrm{I} \mathrm{E}}{23.63} & \frac{23.5 \mathrm{I} \mathrm{E}}{23.57} & 23 . \mathrm{II} \\ 3 & \underline{23.6 \mathrm{I} \mathrm{E}} & \underline{23.4 \mathrm{I} \mathrm{E}} & -\end{array}$

The maximum difference here is 0.16 c.c., equivalent to $0.00008 \mathrm{grm} . \mathrm{CO}_{2}$, which is within the limits of experimental error.

Table VII. Effect of Electrical Discharge upon Seeds.

This table includes preliminary experiments with high current densities. No current measurements were made, but a mercury-platinum electrode was used in each case.

Experiment No.
Estimation No.
I
2
3
4
5
6
7
8
9
I0
I1
12

\begin{tabular}{cc}
21 & 22 \\
0.0228 & 0.0373 \\
0.0180 & 0.0317 \\
0.0147 & 0.0263 \\
0.0130 & $0.0250 \mathrm{E}$ \\
$0.019 \mathrm{IE}$ & 0.0175 \\
\hline $0.018 \mathrm{I}$ & 0.0128 \\
0.0170 & - \\
$0.015 \mathrm{I}$ & - \\
$0.0140 \mathrm{E}$ & - \\
\hline 0.0153 & - \\
0.0125 & - \\
0.0110 & -
\end{tabular}

\begin{tabular}{cc}
25 & 29 \\
0.0248 & 0.0662 \\
0.0199 & $0.044 \mathrm{I}$ \\
0.0172 & $0.0333 \mathrm{E}$ \\
$0.0160 \mathrm{E}$ & 0.0367 \\
\hline 0.0153 & 0.0423 \\
0.0148 & - \\
0.0147 & - \\
$0.0158 \mathrm{E}$ & - \\
\hline 0.0163 & - \\
0.0166 & - \\
0.0159 & - \\
$0.015 \mathrm{I}$ & -
\end{tabular}

Experiment No.
Estimation $N o$.

Continued.

\begin{tabular}{ll}
$\mathbf{1} 37$ & 138 \\
0.0355 & 0.0421 \\
0.0319 & 0.0327 \\
0.0276 & 0.0301 \\
$0.0223 \mathrm{E}$ & 0.0282 \\
\hline $0.025^{2}$ & $0.0230 \mathrm{E}$ \\
0.0220 & 0.0256 \\
\hline & 0.0239
\end{tabular}

Table VIII. Continuation of Table VII.

These results were obtained using a xylol resistance in the electrode (p. I 47 ). In Nos. $8 \mathrm{I}-7$ inclusive the current density was less than $3 \times 10^{-6}$ amperes.

\begin{tabular}{|c|c|c|c|c|c|c|c|}
\hline Experiment No. & $8 I$ & 82 & 83 & 84 & $8_{5}$ & 86 & 87 \\
\hline I & 0.0240 & 0.0203 & 0.0180 & 0.0230 & 0.0260 & 0.0224 & 0.0174 \\
\hline 2 & 0.0177 & 0.0167 & 0.0167 & 0.0168 & 0.0197 & 0.0195 & 0.0154 \\
\hline 3 & 0.0162 & 0.0149 & $0.015^{6}$ & $0.0{ }_{4} 8$ & 0.0168 & 0.0175 & 0.0139 \\
\hline 4 & $0.0{ }_{4}^{8}$ & 0.0I 33 & 0.0150 & 0.0139 & 0.0150 & 0.0158 & $0.013^{2}$ \\
\hline 5 & $0.0138 \mathrm{E}$ & $0.0125 \mathrm{E}$ & $0.0153 \mathrm{E}$ & $0.0135 \mathrm{E}$ & $0.0132 \mathrm{E}$ & $0.0147 \mathrm{E}$ & $0.0126 \mathrm{E}$ \\
\hline 6 & 0.0134 & 0.0121 & 0.0145 & 0.0135 & 0.0125 & $0.013^{8}$ & 0.0122 \\
\hline 7 & 0.0127 & $0.0 I_{1} 4$ & $0.0 I_{4}$ & 0.0135 & 0.0120 & 0.0129 & 0.0116 \\
\hline 8 & 0.0120 & 0.0108 & 0.0140 & o & 0.0113 & $0.012 I$ & 0.0112 \\
\hline
\end{tabular}

There is an indication in Experiments $81,82,83,84$, and $8_{5}$ that electrification has caused a modification in the respiration curve, but the change was so slight as to be almost within the limits of experimental error, and was therefore deemed insignificant. 
Experiment No. $\quad 88$

Estimation No.

I
2
3
4
5
6
7
8

TABLE VIII. Continued.

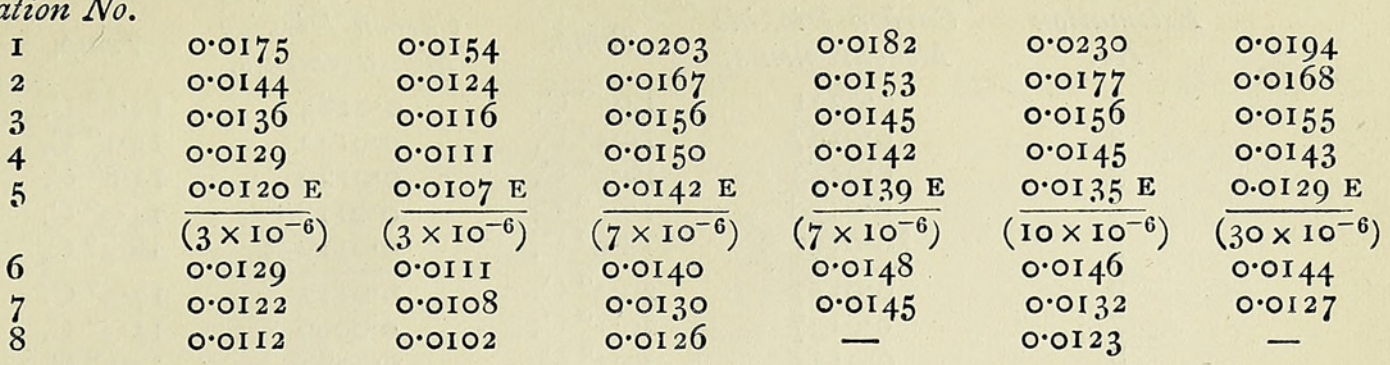

Table IX. Effect of the Products of Discharge upon Peas.

\begin{tabular}{|c|c|c|c|c|c|}
\hline $\begin{array}{l}\text { Experiment No. } \\
\text { Estimation No. }\end{array}$ & $120^{*}$ & I $2 I^{*}$ & $122^{*}$ & I $23^{*}$ & $124^{*}$ \\
\hline I & 0.0304 & 0.0230 & 0.0293 & 0.0249 & 0.0407 \\
\hline 2 & 0.0254 & 0.0154 & $0.025^{\mathrm{I}}$ & 0.0204 & 0.0253 \\
\hline 3 & 0.0208 & $0.013^{2}$ & 0.0213 & 0.0183 & 0.02 II \\
\hline 4 & 0.0170 & $0.0132 \mathrm{E}$ & 0.0177 & 0.0164 & 0.0180 \\
\hline 5 & $0.0143 \mathrm{E}$ & 0.0118 & $0.0156 \mathrm{E}$ & $0.0152 \mathrm{E}$ & $0.0160 \mathrm{E}$ \\
\hline 6 & 0.0125 & 0.0105 & 0.0139 & 0.0143 & 0.0145 \\
\hline 7 & 0.0112 & - & 0.0130 & 0.0137 & 0.0133 \\
\hline 8 & O.OIOI & - & 0.0125 & 0.0133 & 0.0127 \\
\hline
\end{tabular}

N.B.-A strip of paper moistened with a solution of starch and potassium iodide indicated the presence of the oxidizing gases in the second chamber almost immediately after switching on the discharge in the first, but none could be detected in the tubes between the peas and the baryta solution.

\section{Table X. Effect of Continued Discharge. Platinum-Mercury Contact} ELECTRODE.

Experiment No. Estimation No.

$\begin{array}{lll}1 & 0.0293 & 0.0240 \\ 2 & 0.0243 & 0.0187 \\ 3 & 0.0212 & 0.0159 \\ 4 & 0.019 \mathrm{I} & 0.0143 \\ 5 & \frac{0.0183 \mathrm{E}}{0.0190 \mathrm{E}} & \frac{0.0120 \mathrm{E}}{0.0153 \mathrm{E}} \\ 6 & \frac{0.0185 \mathrm{E}}{0.0210 \mathrm{E}} \\ 7 & \frac{0.018 \mathrm{IE}}{0.0172 \mathrm{E}} & \frac{0.036 \mathrm{IE}}{-} \\ 8 & \frac{0.0168 \mathrm{E}}{10 .} & -\end{array}$

No temperature readings were taken, but in No. 97 the final temperature was noticeably very much above room temperature.

\section{Table XI. Continuation of Table X.}

In the following experiments temperatures were taken, and on the correction of temperature changes the curves follow a normal course.

The carbon dioxide figures given are those actually measured.

\begin{tabular}{|c|c|c|c|c|c|c|}
\hline \multicolumn{3}{|c|}{ Experiment No. } & \multicolumn{2}{|c|}{106} & \multicolumn{2}{|c|}{ I I 8} \\
\hline $\begin{array}{c}\text { Estimation } \\
\text { No. }\end{array}$ & $\begin{array}{l}\text { Carbon Dioxide } \\
\text { Measurements. }\end{array}$ & Temp. & $\begin{array}{l}\text { Carbon Dioxide } \\
\text { Measurements. }\end{array}$ & & $\begin{array}{l}\text { Carbon Dioxide } \\
\text { Measurements. }\end{array}$ & Temp. \\
\hline I & 0.0209 & $10.8^{\circ} \mathrm{C}$. & $0.0 I_{40}$ & $\mathrm{I}_{4} \cdot 2^{\circ} \mathrm{C}$. & 0.0316 & 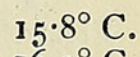 \\
\hline 2 & 0.0165 & $\mathrm{II} \cdot 2^{\circ} \mathrm{C}$. & 0.0126 & $\mathrm{I}^{4} \cdot 2^{\circ} \mathrm{C}$. & 0.02 I I & I $6.5^{\circ}$ \\
\hline 3 & 0.0154 & I $1 \cdot 7^{\circ} \mathrm{C}$. & O.OII 5 & $13.3^{\circ} \mathrm{C}$. & 0.0182 & $I 7 \cdot I^{\circ}$ \\
\hline 4 & 0.0148 & $12 \cdot 1^{\circ} \mathrm{C}$. & 0.0108 & $13.5^{\circ} \mathrm{C}$. & 0.0172 & $17 \cdot 6^{\circ}$ \\
\hline 5 & $0.0130 \mathrm{E}$ & I $2 \cdot 2^{\circ} \mathrm{C}$. & $0.0107 \mathrm{E}$ & $16.4^{\circ} \mathrm{C}$. & $0.0159 \mathrm{E}$ & $17 \cdot 8^{\circ} \mathrm{C}$ \\
\hline 6 & $\overline{0.0142 \mathrm{E}}$ & I $2.8^{\circ} \mathrm{C}$. & 0.0101 & $16 \cdot 4^{\circ} \mathrm{C}$. & 0.0149 & $17.8^{\circ} \mathrm{C}$ \\
\hline 7 & $-\quad E$ & $\mathrm{I} 3.7^{\circ} \mathrm{C}$. & 0.0094 & $16 \cdot 1^{\circ} \mathrm{C}$ & 0.0142 & $\mathrm{I} 7 \cdot 8^{\circ}$ \\
\hline 8 & $\overline{0.0150 \mathrm{E}}$ & $\mathrm{I}_{4} \mathrm{I}^{\circ} \mathrm{C}$. & 0.0086 & ${ }^{\prime} 5 \cdot 6^{\circ} \mathrm{C}$. & $0.013^{8}$ & $17 \cdot 9^{\circ}$ \\
\hline
\end{tabular}

N.B.-In No. IO2 the temperature of the upper layers of seeds was higher than those given, which were recorded about the centre of the mass. This explains the fact that in this case the corrected figures all lie slightly above the normal curve. 
TABLE XI. Continued.

\begin{tabular}{|c|c|c|c|c|}
\hline \multirow{2}{*}{$\begin{array}{c}\text { Experiment } \\
\text { Estimation } \\
\text { No. }\end{array}$} & \multicolumn{2}{|c|}{ I I 9} & \multicolumn{2}{|c|}{107} \\
\hline & $\begin{array}{l}\text { Carbon Dioxide } \\
\text { Measurements. }\end{array}$ & Temp. & $\begin{array}{l}\text { Carbon Dioxide } \\
\text { Measurements. }\end{array}$ & Temp. \\
\hline I & 0.0321 & $14.7^{\circ} \mathrm{C}$. & 0.0183 & I $2.8^{\circ} \mathrm{C}$. \\
\hline 2 & 0.0187 & I $5.5^{\circ} \mathrm{C}$. & 0.0142 & $\mathrm{I}_{3} \cdot^{\circ} \mathrm{C}$. \\
\hline 3 & 0.0143 & I6. $5^{\circ} \mathrm{C}$. & 0.0129 & $13.8^{\circ} \mathrm{C}$. \\
\hline 4 & $0.013^{8}$ & I6. $9^{\circ} \mathrm{C}$. & 0.0118 & $14.3^{\circ} \mathrm{C}$. \\
\hline 5 & $? 0.0127 \mathrm{E}$ & $18 \cdot 9^{\circ} \mathrm{C}$. & $0.0116 \mathrm{E}$ & $18.5^{\circ} \mathrm{C}$ \\
\hline 6 & 0.0157 & $20.3^{\circ} \mathrm{C}$. & 0.0112 & $17.5^{\circ} \mathrm{C}$. \\
\hline 7 & 0.0137 & $20 \cdot \mathrm{I}^{\circ} \mathrm{C}$. & 0.0096 & I $5.3^{\circ} \mathrm{C}$. \\
\hline 8 & 0.0134 & $20 \cdot 2^{\circ} \mathrm{C}$. & 0.0086 & $\mathrm{I}_{4} 7^{\circ} \mathrm{C}$. \\
\hline
\end{tabular}

Table XII. Experiments 98 and 99. (See text.)

Experiment No.

Estimation Carbon Dioxide No. Measurements.

$\begin{array}{ll}\mathrm{I} & 0.0152 \\ 2 & 0.0129 \\ 3 & 0.0118 \\ 4 & 0.0112 \\ 5 & 0.0112 \mathrm{E} \\ 6 & 0.0126 \mathrm{E} \\ 7 & 0.0138 \\ 8 & 0.0110\end{array}$

$9^{8}$

Temp. Corrected Carbon Dioxide
Values. Measurements. $13.9^{\circ} \mathrm{C} . \quad 0.015^{2}$ I $4.7^{\circ} \mathrm{C} . \quad 0.0119$ I $5.3^{\circ} \mathrm{C}$. 0.0104 I $5.8^{\circ} \mathrm{C} . \quad 0.0094$ I $6.8^{\circ} \mathrm{C} . \quad 0.0087$ I $8 \cdot 6^{\circ} \mathrm{C} . \quad 0.0086$ I $9.3^{\circ} \mathrm{C} . \quad 0.0090$ $18 \cdot 3^{\circ} \mathrm{C} . \quad 0.0076$

0.0188
0.0147
0.0129
0.0127
0.0129
0.0143
0.0160
0.0145

99

Temp. Corrections to

$\begin{array}{ll}13.9^{\circ} \mathrm{C} . & = \\ 14.7^{\circ} \mathrm{C} . & = \\ 15.3^{\circ} \mathrm{C} . & = \\ 15.8^{\circ} \mathrm{C} . & - \\ 16.8^{\circ} \mathrm{C} . & - \\ 18.6^{\circ} \mathrm{C} . & - \\ 19.8^{\circ} \mathrm{C} . & 0.015^{2} \\ 19.4^{\circ} \mathrm{C} . & 0.0130\end{array}$

Table Xili. Attempts to prevent Rise of Temperature. (See text.)

Numbers represent mean temperatures for half-hour periods.

Experiment No.

Estimation No.

$\begin{array}{ll}\mathrm{I} & \mathrm{I} 3.0^{\circ} \mathrm{C} . \\ 2 & 13.3^{\circ} \mathrm{C} . \\ 3 & 13.3^{\circ} \mathrm{C} . \\ 4 & 13.9^{\circ} \mathrm{C} . \\ 5 & \frac{142^{\circ} \mathrm{C} . \mathrm{E}}{\mathrm{I} 4^{\circ} \mathrm{C} . \mathrm{E}} \\ 6 & \frac{\mathrm{I} 47^{\circ} \mathrm{C} . \mathrm{E}}{-} \\ 7 & -\end{array}$

104

\begin{tabular}{l} 
I $3.3^{\circ} \mathrm{C}$. \\
I $3.8^{\circ} \mathrm{C}$. \\
I $4.3^{\circ} \mathrm{C}$. \\
I $4.6^{\circ} \mathrm{C}$. \\
I $5 \cdot 0^{\circ} \mathrm{C} . \mathrm{E}$ \\
\hline I $7 \cdot 2^{\circ} \mathrm{C}$. \\
I $6.9^{\circ} \mathrm{C}$. \\
I $6.6^{\circ} \mathrm{C}$
\end{tabular}

105

\begin{tabular}{l} 
I $4.2^{\circ} \mathrm{C}$. \\
I $4.3^{\circ} \mathrm{C}$ \\
I $4.7^{\circ} \mathrm{C}$. \\
I $5.3^{\circ} \mathrm{C}$. \\
$16.4^{\circ} \mathrm{C} . \mathrm{E}$ \\
\hline $\mathrm{I} 6.9^{\circ} \mathrm{C}$. \\
I $6.4^{\circ} \mathrm{C}$. \\
$15.8^{\circ} \mathrm{C}$.
\end{tabular}

I03. Chamber in a water-bath. Temperatures of lower layers of seeds recorded. Final temperature of upper layers $18 \cdot 6^{\circ} \mathrm{C}$.

104. Seeds covered with glass wool. Temperatures of upper layers recorded. recorded.

I05. Glass wool and dead seeds over live seeds. Temperatures of upper layers of living seeds

Table XiV. Temperature Changes of Dead Peas under Electrical Discharge.

\begin{tabular}{|c|c|c|c|c|}
\hline & ০ & & IOI & \\
\hline Time. & Temp. & Time. & Room Temp. & Temp. of Seed. \\
\hline 3.20 & $8 \cdot 9^{\circ} \mathrm{C}$. & $9 \cdot 55$ & $12 \cdot 2^{\circ} \mathrm{C}$. & $12 \cdot 2^{\circ} \mathrm{C}$. \\
\hline 3.40 & $10.0^{\circ} \mathrm{C}$. & I0.10 & I $2 \cdot 2^{\circ} \mathrm{C}$. & $\mathrm{I} 2 \cdot 2^{\circ} \mathrm{C}$. \\
\hline 4.0 & II $\cdot I^{\circ} \mathrm{C}$. & 10.25 & I $2 \cdot 2^{\circ} \mathrm{C}$. & $12 \cdot 2^{\circ} \mathrm{C}$. \\
\hline 4.15 & $\mathrm{II} \cdot 7^{\circ} \mathrm{C}$. & 10.40 & I $2.8^{\circ} \mathrm{C}$. & $12.2^{\circ} \mathrm{C}$. \\
\hline $4 \cdot 30$ & $12 \cdot 2^{\circ} \mathrm{C}$. & 10.55 & I $2.8^{\circ} \mathrm{C}$. & $12.8^{\circ} \mathrm{C}$ \\
\hline Electrification & Thermometer bulb & I I.I 5 & I $2.8^{\circ} \mathrm{C}$. & I $2.8^{\circ} \mathrm{C}$. \\
\hline continuous. & at the bottom of & I I.3O & $\mathrm{I} 3 \cdot 3^{\circ} \mathrm{C}$. & $13.3^{\circ} \mathrm{C}$. \\
\hline & the chamber. & 11.40 & I $3.3^{\circ} \mathrm{C}$. & $\mathrm{I} 3.3^{\circ} \mathrm{C}$. \\
\hline & Final temp. of top & I I. 55 & $13.3^{\circ} \mathrm{C}$. & $\mathrm{I} 3.9^{\circ} \mathrm{C}$. \\
\hline & I $7 \cdot 8^{\circ} \mathrm{C}$.; of & I 2.10 & I $3.9^{\circ} \mathrm{C}$. & $13.9^{\circ} \mathrm{C}$. \\
\hline & centre $16.7^{\circ} \mathrm{C}$. & 12.30 & $14.4^{\circ} \mathrm{C}$. & $13.9^{\circ} \mathrm{C}$. \\
\hline & & I 2.50 & $14.4^{\circ} \mathrm{C}$ & $14.4^{\circ} \mathrm{C}$. \\
\hline
\end{tabular}


Table XV. Controls with Apparatus for Electrical Discharge upon

Seedlings. No Electrification.

\begin{tabular}{|c|c|c|c|c|c|}
\hline Experiment No. & Io8 (Wheat) & I 25 (Wheat)* & I 26 (Wheat)* & I 3 I (Rye) & ${ }^{1} 3^{2}$ (Wheat)* \\
\hline I & - & 0.0120 & 一 & 0.0087 & 0.00391 \\
\hline 2 & 0.0025 & $0.01 I_{5}$ & 一 & 0.0095 & 0.0039 Total \\
\hline 3 & 0.0026 & 0.0110 & $0.013 I$ & 0.0092 & $0.0033\left[0.0 I_{4} \mathrm{I}\right.$ \\
\hline 4 & 0.0029 & 0.0110 & $0.013 \mathrm{I}$ & - & $0.0030)$ \\
\hline 5 & 0.0030 & - & 0.0125 & - & 0.0136 \\
\hline 6 & 0.0029 & - & 0.0121 & 一 & 0.0132 \\
\hline 7 & $0.003 \mathrm{I}$ & - & - & - & - \\
\hline 8 & 0.0030 & - & - & 一 & - \\
\hline
\end{tabular}

No. I08. 30-minute periods.

Nos. 125 and 126 . 60 -minute periods.

No. I3I. I 20 -minute periods.

No. I 32 . I, 2, 3, and 4, 30-minute periods; 5 and 6, I 20 -minute periods.

Table XVI. Electrical Discharge upon Seedlings.

\begin{tabular}{|c|c|c|c|c|c|c|c|}
\hline Experiment No & $\begin{array}{c}\text { 109* } \\
\text { (Wheat) }\end{array}$ & $\begin{array}{c}\text { I10* } \\
\text { (Wheat) }\end{array}$ & $\begin{array}{c}\text { I I I* } \\
\text { (Wheat) }\end{array}$ & $\begin{array}{r}\text { I I } 2^{*} \\
\text { (Peas) }\end{array}$ & $\begin{array}{c}\text { I33 } \\
\text { (Wheat) }\end{array}$ & $\begin{array}{c}134^{*} \\
\text { (Wheat) }\end{array}$ & $\begin{array}{c}\text { I3 } 35^{*} \\
\text { (Wheat) }\end{array}$ \\
\hline I & 0.0133 & 0.0117 & 0.0120 & 0.0091 & 0.0137 & $c .0130$ & 0.0129 \\
\hline 2 & $\frac{0.013^{2} \mathrm{E}}{\left(10^{-6}\right)}$ & $\frac{0.0116 \mathrm{E}}{\left(3 \times 10^{-6}\right)}$ & $\frac{0.0119 \mathrm{E}}{\left(3 \times 10^{-6}\right.}$ & $\frac{0.009^{8 \mathrm{E}}}{\left(10 \times 10^{-6}\right)}$ & $\frac{0.0139 \mathrm{E}}{\left(10 \times 10^{-6}\right)}$ & $\frac{0.0129 \mathrm{E}}{\left(6 \times 10^{-6}\right)}$ & $\frac{0.0121 \mathrm{E}}{\left(10 \times 10^{-6}\right)}$ \\
\hline
\end{tabular}

I 20-minute periods in all cases.

No. I I2. Discharge applied for ten minutes only on account of the passage of sparks to the plants. This probably caused the increase in carbon dioxide production owing to a large local rise of temperature which would be unrecorded.

\section{Table XVII. Effect of the Gaseous Products of Discharge upon Wheat} SeEdlings.

$\begin{array}{clllc}\text { Experiment } N_{0}^{\top} . & \mathrm{I} 27^{*} & \mathrm{I} 28^{*} & \mathrm{I} 29^{*} & \mathrm{I} 30^{*} \\ \text { Estimation No. } & 0.0302 & 0.0 \mathrm{I} 39 & 0.0100 & 0.0 \mathrm{I} 5 \mathrm{I} \\ \mathrm{I} & 0.026 \mathrm{I} & 0.0 \mathrm{I} 34 & 0.0 \mathrm{I} 67 \mathrm{E} & 0.0 \mathrm{I} 52 \mathrm{E} \\ 2 & 0.0283 \mathrm{E} & 0.0 \mathrm{I} 50 \mathrm{E} & - & -\end{array}$

No. I27. Temperature correction for 2 was large, and would probably account for the difference between $I$ and 2 .

Nos. 127 and I 28 . Electrification 30 minutes.

No. I 29. Electrification I5 minutes.

No. I30. Electrification 5 minutes.

\section{Table XVIII. Effect of the Products of the Discharge upon the Baryta Solution.}

The figures given are the oxalic acid equivalent of ro c.c. of the baryta solution after the passage of the air-stream.

\section{Experiment No. \\ Conditions of Experiment.}

I. No discharge

2. Discharge over dead peas

3. Discharge in empty chamber

$\begin{array}{ll}139 & \text { I } 40 \\ 29 \cdot 66 & 26 \cdot 39 \\ 29 \cdot 60 & 26 \cdot 34 \\ 29 \cdot 43 & 26 \cdot 17\end{array}$




\section{$2 \mathrm{BHL}$ Biodiversity Heritage Library}

Knight, R. C. and Priestley, J. H. 1914. "The respiration of plants under various electrical conditions." Annals of botany 28, 135-161. https://doi.org/10.1093/oxfordjournals.aob.a089492.

View This Item Online: https://www.biodiversitylibrary.org/item/236856

DOI: https://doi.org/10.1093/oxfordjournals.aob.a089492

Permalink: https://www.biodiversitylibrary.org/partpdf/320013

\section{Holding Institution}

Smithsonian Libraries

\section{Sponsored by}

Biodiversity Heritage Library

\section{Copyright \& Reuse}

Copyright Status: Not in copyright. The BHL knows of no copyright restrictions on this item.

This document was created from content at the Biodiversity Heritage Library, the world's largest open access digital library for biodiversity literature and archives. Visit BHL at https://www.biodiversitylibrary.org. 